\title{
Re-Recognition of Garden Index as a Criterion for Evaluating the Quality of Femoral Neck Fracture Reduction: An Imaging Study Based on Cadaver Specimens
}

\section{Leyi Cai}

The Second Affiliated Hospital and Yuying Children's Hospital of Wenzhou Medical University

\section{Wenjie Li}

The Second Clinical Medical College of Wenzhou Medical University

\section{Wenhao Zheng}

Yuying Children's Hospital of Wenzhou Medical College: Wenzhou Medical University Second Affiliated Hospital

\section{Jianshun Wang}

The Second Affiliated Hospital and Yuying Children's Hospital of Wenzhou Medical University

\section{Xiaoshan Guo}

Yuying Children's Hospital of Wenzhou Medical College: Wenzhou Medical University Second Affiliated Hospital

\section{yongzeng feng ( $\nabla$ fengyongzeng@sina.com )}

The Second Affiliated Hospital and Yuying Children's Hospital of Wenzhou Medical University

\section{Research article}

Keywords: Garden index, femoral neck fracture, rotational displacement, imaging study

Posted Date: January 21st, 2021

DOI: https://doi.org/10.21203/rs.3.rs-150244/v1

License: (a) This work is licensed under a Creative Commons Attribution 4.0 International License. Read Full License 


\section{Abstract}

Objective

To investigate whether the Garden index can determine the rotational displacement of femoral neck fracture.

Methods

Ten healthy human femoral specimens were obtained. A $2.0 \mathrm{~mm}$ diameter Kirschner-wire was placed in the center of the femoral head. The osteotomy was perpendicular in the middle of the femoral neck. The distal osteotomy surface was indicated the angle of rotation (pronation and supination to $90^{\circ}$, every $10^{\circ}$ was an interval). The X-ray of anterior-posterior and lateral view was taken at different angles according to the mark. The Garden index and other relevant data were analyzed with the PCAS system. Meanwhile, the change of the area of the femoral head fovea at different rotation angles was observed.

Results

There was no significant difference in the Garden index in $0 \sim 30^{\circ}$ at pronation and supination position $(P>0.05)$. In range of $40^{\circ} \sim 90^{\circ}$, there was a statistical difference in the Garden index $(P<0.05)$. With the increase of the pronation angle, the area of the femoral head fovea is gradually reduced; as the angle of the supination increases, the area of the femoral head fovea is gradually increased.

Conclusion

The Garden Index cannot accurately determine the rotational displacement of the femoral neck fracture during the pronation or supination range of $0 \sim 30^{\circ}$. Changes in the area of the femoral head fovea can help determine the rotational displacement of the femoral neck fracture.

Level of Evidence

Level V.

\section{Introduction}

Femoral neck fractures are one of the most common types of fractures in the clinic. Elderly patients with displaced femoral neck fractures can achieve good results by applying joint replacement surgery. In young people with femoral neck fractures, internal fixation operation is often chosen. However, certain complications often occur after internal fixation, such as traumatic femoral head necrosis, hip pain, function limitation, and fracture nonunion [1, 2], which result in a heavy economic and social burden to the patient and the family. Some scholars suggest that the quality of the reduction of the femoral neck fracture will affect the consequent of the internal fixator and the probability of secondary surgery after internal fixation of the femoral neck fracture [3-5]. Although the open reduction of the femoral neck 
fracture can achieve anatomical reduction, there is a greater damage to the local blood supply, which easily damages the blood supply system of the femoral head, and lead to the postoperative avascular necrosis of the femoral head $[6,7]$. Therefore, the current clinical reduction of femoral neck fractures is often based on intraoperative C-arm fluoroscopy for closed reduction [8].

How to accurately judge whether the reduction of the femoral neck fracture during surgery is good in the closed state. The previous literature proposed various methods, such as: the Garden Index [9], Lindquist and Tornkvist's standard [10], the Western Infirmary Glasgow (WIG) Angle [11]. Among them, the Garden index is the most classic. The index was first proposed by Garden in the 1964, and it was mentioned again in the literature of 1971 [4] and 1974 [12]. It was later called the Garden Index. The anterior and lateral X-ray angle measurement is defined as: In the antero-posterior radiograph these the fan-shaped medial group of trabeculae in the head of the femur normally lie in alignment with their projections in the adjacent pelvis, and a line drawn through the long axis of the group forms an angle of approximately 160 degrees with the medial cortex of the femoral shaft (Fig. 1). In the lateral view the central axis of the head and the central axis of the neck lie in the same straight line (Fig. 1). The normal antero-posterior/lateral relationship of the two fragments can thus be expressed as an alignment index of $160 / 180$. This reduction standard has been widely cited in the following clinical and literature and has become the most classic standard method for reduction of femoral neck fractures in clinical practice.

In the internal fixation operation of femoral neck fractures, anatomical reduction plays an important role in restoring blood supply after femoral neck fracture. Min et al [15] reported that the necrotic rate of unsatisfactory reduction after femoral neck fracture was $68.8 \%$. Garden [12] also believes that malreduction of the femoral neck fracture will increase the rate of necrosis of the femoral head. Wang et al. [16] also found that Garden line index and necrosis rate of femoral head after internal fixation operation had a significant correlation $(\mathrm{OR}=3.475, \mathrm{P}=0.006)$, indicating that the worse the garden index, the worse the patient's prognosis. All of the above studies suggest that we should undergo more fluoroscopy and repeated fluoroscopy during the operation, as soon as possible to achieve anatomic reduction, which can reduce the incidence of femoral head necrosis. However, Min et al [15] also reported that the satisfactory postoperative reduction of femoral neck fracture but still had a $20 \%$ femoral head necrosis rate. At the same time, the author also found some patients with a satisfactory Garden index after operation still suffered from traumatic femoral head necrosis in long-term follow-up. In addition to the commonly recognized factors (such as age, fracture classification, internal fixation options, etc.), is there still a rotatory displacement in the fracture line? Can the currently used Garden Index judge the rotatory displacement of the femoral neck? In this study, based on the anatomy of cadaver specimens, a rotatory displacement model of the femoral neck fracture was made. Then, according to the definition of the Garden Index angle measurement, it is clear whether it can judge the rotatory displacement of the femoral neck.

\section{Materials And Methods}


This study was done at the Second Affiliated Hospital and Yuying Children's Hospital of Wenzhou Medical University in Wenzhou, Zhejiang, China and permission was obtained from the hospital Ethics Committee.

\section{Material}

Five specimens of 10 upper femurs (no restrictions for men and women) are provided by the Department of Anatomy, Wenzhou Medical University. The specimens of the corpses in the area are all healthy adult cadaver specimens. The adult pelvis is visually observed and X-ray confirmed no obvious abnormalities, osteoporosis, old fractures and other abnormalities, and remove the surrounding soft tissues.

\section{Specimen production method}

A $2.0 \mathrm{~mm}$ diameter Kirschner wire was drilled into the center of the femoral head toward the lateral wall of the femur, parallel to the long axis of the femoral neck. Then, a marker line on the long axis of the femoral neck was made on the surface of the specimen, and the midpoint perpendicular line of the marker line was used as the osteotomy line to perform vertical femoral neck osteotomy (Figure 2). The intersection of the distal osteotomy surface of the femoral neck and the marked long axis of the femoral neck was used as a $0^{\circ}$ scale line, and the protractor was used to measure on the osteotomy surface, $10^{\circ}$ is an interval, marked to the left and right, from $0^{\circ}$ to $90^{\circ}$ (Figure 3). Then, the distal femur of the osteotomy surface was fixed with an acrylic resin on the standard anterior and lateral position, and the proximal femoral head of the osteotomy surface was sequentially rotated and rotated with the Kirschner wire as the center. A rotational model of the femoral neck fracture was made, with a clockwise rotation of the proximal femoral head of the osteotomy surface as the pronation; a counterclockwise rotation for supination (Fig. 4)

\section{Measurement methods}

Select the neutral position $\llbracket$ pronation and supination $0^{\circ}, 10^{\circ}, 20^{\circ}, 30^{\circ}, 40^{\circ}, 50^{\circ}, 70^{\circ}, 90^{\circ}$ for the anterior and lateral X-ray photography \and the distal fragment was in the neutral position (Fig. 5, 30 ${ }^{\circ}$ after the pronation or supination). The image is uploaded and stored in our PACS imaging system, and its own angle measurement tool is used to measure and calculate the garden index for each angle of the x-ray film. At the same time, the area of the femoral head fovea was measured using the measurement function of the PACS during the rotation.

Data processing and analysis: All data were statistically processed using SPSS 19.0 statistical software package, and the practical mean \pm standard deviation was expressed. There was a statistical difference between $p<0.05$. The garden index of multiple groups was compared by analysis of variance (ANOVA). After determining the statistical difference between the groups, the Tukey HSD method was further used for comparison.

\section{Results}




\section{The garden index cannot determine the rotatory displacement of a femoral neck fracture within a certain}

range.

1. Anterior-posterior view $₫ A$ total of 10 cadaver specimens, from $0^{\circ}$ pronation to $90^{\circ}$, analysis of variance showed statistical differences between the garden indices $(p<0.01)$. Further Tukey HSD method showed that there was no significant different in the garden index on the $x$-ray during the $0^{\circ}$ to $30^{\circ}$ process $(p>0.05)$, and the values were all greater than $155^{\circ}$; During the rotation from $40^{\circ}$ to $90^{\circ}$, the garden index showed a significant different $(p<0.05)$, and the values were all less than $155^{\circ}$, as shown in Figure 6.

2. Anterior-posterior view $₫ A$ total of 10 cadaver specimens, from $0^{\circ}$ supination to $90^{\circ}$, analysis of variance showed statistical differences between the garden indices $(p<0.01)$. Further Tukey HSD method showed that there was no significant difference in the garden index on the $x$-ray during the $0^{\circ}$ to $30^{\circ}$ supination $(p>0.05)$, and the values were all greater than $155^{\circ}$; During the supination from $40^{\circ}$ to $90^{\circ}$, the garden index showed a significant difference $(p<0.05)$, and the values were all less than $155^{\circ}$, as shown in Figure 7.

3. Lateral view $\varangle A$ total of 10 cadaver specimens, from $0^{\circ}$ pronation to $90^{\circ}$, analysis of variance showed statistical differences between the garden indices $(p<0.01)$. Further Tukey HSD method showed that there was no significant change in the garden index on the x-ray during the $0^{\circ}$ to $30^{\circ}$ process $(p>0.05)$; During the pronation from $40^{\circ}$ to $90^{\circ}$, the garden index showed a significant difference $(p<0.05)$, as shown in Figure 8.

4. Lateral view $₫ A$ total of 10 cadaver specimens, from $0^{\circ}$ supination to $90^{\circ}$, analysis of variance showed statistical differences between the garden indices $(p<0.01)$. Further Tukey HSD method showed that there was no significant difference in the garden index on the x-ray during the $0^{\circ}$ to $30^{\circ}$ process ( $p>0.05$ ); During the supination from $40^{\circ}$ to $90^{\circ}$, the garden index showed a significant change $(p<0.05)$, as shown in Figure 9.

\section{Changes in the Fovea area of femoral head can indicate a rotator displacement in the femoral neck fracture}

1. Changes in the fovea area of femoral head in the anterior-posterior view: During the rotation from $0^{\circ}$ to $90^{\circ}$ pronation, the fovea area of the femoral head gradually became smaller until it finally disappeared. After $60^{\circ}$ of the pronation, the existence of the fovea of femoral head was not observed, and the area measurement could not be performed (Figure 10).

2. Changes in the fovea area of femoral head in the anterior-posterior view: During the rotation from $0^{\circ}$ to $90^{\circ}$ supination, the fovea area of femoral head gradually increases until it is "embedded" inside the femoral head, and the trend is reduced (Figure 11).

\section{Discussion}

After internal fixation of femoral neck fracture, traumatic necrosis of the femoral head is still a major complication. How to reduce the rate of necrosis is a major problem in Orthopaedic Trauma[17, 18]. The 
blood supply of the femoral head is mainly from the medial and lateral femoral circumflex artery. The fracture is usually accompanied by the distortion, deformation and obstruction of the blood vessels in the femoral neck region. At the same time, the pressure increase in the joint capsule after the fracture which further reduces the blood supply to the femoral head, avascular necrosis of the femoral head occurs when residual blood supply is not compensated $[19,20]$. Therefore, the quality of the reduction of the femoral neck fracture is related to the blood supply of the femoral head. The anatomical reduction of the femoral neck fracture can provide the best environment for the revascularization of the femoral head [21]. How to improve the quality of fracture reduction during surgery is particularly important [5].

The garden index was first proposed by Garden [9] in 1964 and is still the classic standard for clinical reduction of femoral neck fractures. The specific content is: In the antero-posterior radiograph these the fan-shaped medial group of trabeculae in the head of the femur normally lie in alignment with their projections in the adjacent pelvis, and a line drawn through the long axis of the group forms an angle of approximately 160 degrees with the medial cortex of the femoral shaft. In the lateral view the central axis of the head and the central axis of the neck lie in the same straight line. The normal anteroposterior/lateral relationship of the two fragments can thus be expressed as an alignment index of 160/180. At the same time, Garden [4] also pointed out that regardless of the anterior-posterior or lateral position, the femoral head necrosis rate of the garden index between $155^{\circ}$ and $180^{\circ}$ is $6.6 \%(16 / 242)$, less than $155^{\circ}$, or more than $180^{\circ}$, will greatly increase the incidence of femoral head necrosis, from $65.5 \%(53 / 81)$ to $100 \%(26 / 26)$. As a classic rule for evaluating the reduction quality of femoral neck fractures, the garden index is still adopted by most orthopaedic surgeons.

However, the Garden Index is a measurement based on a two-dimensional plane, and it does not make explicit provisions for rotatory displacement of the femoral neck in three-dimensional space. Therefore, we used imaging studies of cadaver specimens to determine whether the garden index can determine the rotatory displacement of femoral neck fractures. We found that within the range of pronation $30^{\circ}$ or supination $30^{\circ}$, the garden index did not change significantly, and there was no statistical difference. Therefore, we believe that the rotatory displacement of femoral neck fractures within $30^{\circ}$, the garden index cannot be accurately judged. The rotatory displacement from $40^{\circ}$ to $90^{\circ}$ shows a significant change in the garden index no matter whether it is pronation or supination. According to our analysis, $X$ ray is a two-dimensional planar image, but the femoral neck rotatory displacement in three-dimensional space cannot be accurately judged, Only when the rotatory angle increases to a certain degree and there is obvious misalignment, the garden index will change to some extent. This also prompts us to use the garden index to evaluate the reduction quality is not completely reliable. We need more accurate instruments such as intraoperative 3D CT to more accurately display the reduction quality of femoral neck fractures.

We have also found some imaging markers in repeated research, in order to assist in determining the rotatory displacement of femoral neck fractures during surgery. We initially found that during the proximal rotation of the femoral neck fracture, the fovea area of femoral head on the anterior-posterior view showed a certain change law, which can help judge the rotation of the femoral neck fracture during 
the operation. The fovea of femoral head is located at the center of the femoral head and connects the round ligament. With the rotation of the femoral head, the fovea of femoral head appears on the twodimensional image of the X-ray, showing an increase or decrease in area. In the process of femoral neck fracture reduction, it can be used to help judge the change of rotation.

However, how many degrees of rotatory displacement will affect the blood supply of the femoral head and then cause necrosis of the femoral head? There are currently no relevant literature reports. We will use animal experiments and clinical case follow-up studies for further verification in future studies.

\section{Abbreviations}

PCAS『Picture Archiving and Communication Systems

ANOVA囚analysis of variance

\section{Declarations}

\section{Acknowledgements}

This study was supported by National Natural Science Foundation of China (No. 81701928). The funders had no role in the study design, data collection and analysis, decision to publish, or preparation of the manuscript.

\section{Authors' contributions $\square$}

Leyi Cai and Yongzeng Feng contributed to the idea and design. Wenjie Li, Wenhao Zheng and Jianshun Wang contributed to the data acquisition and analysis. Leyi Cai, Xiaoshan Guo and Yongzeng Feng contributed to the manuscript writing and revision. All authors contributed to data acquisition and analysis and to manuscript writing and revision, and agreed to all aspects of the work.

\section{Funding:}

This study was supported by National Natural Science Foundation of China (No. 81701928).

\section{Availability of data and materials:}

Patient data comes from our hospital's medical records follow-up database, transparent and available

\section{Ethics approval and consent to participate:}

This study followed the guidelines of the "Declaration of Helsinki" and was approved by the hospital's ethics committee.

\section{Consent for publication:}


Not applicable.

\section{Conflict of Interest:}

The authors declare that they have no conflict of interest.

\section{Author details:}

1: Department of Orthopaedics Surgery, The Second Affiliated Hospital and Yuying Children's Hospital of Wenzhou Medical University. Full postal address: N0.109, XueYuan West Road, Luheng District, Wenzhou, Zhejiang Province, 325000, P.R. China.

2: The Second Clinical Medical College of Wenzhou Medical University, Wenzhou, Zhejiang Province, 325000, P.R. China.

\section{References}

1. Slobogean GP, Sprague SA, Scott T, Bhandari M. Complications following young femoral neck fractures. Injury. 2015;46(3):484-91.

2. Della Rocca GJ. Gaps and opportunities in the management of the young femoral neck fracture. Injury. 2015;46(3):515-8.

3. Parker MJ. The management of intracapsular fractures of the proximal femur.The Journal of bone and joint surgery British volume. 2000;82(7):937-41.

4. Garden RS. Malreduction and avascular necrosis in subcapital fractures of the femur.The Journal of bone and joint surgery British volume. 1971;53(2):183-97.

5. Parker MJ. Prediction of fracture union after internal fixation of intracapsular femoral neck fractures. Injury. 1994;25 Suppl 2:B3-6.

6. Upadhyay A, Jain P, Mishra P, Maini L, Gautum VK, Dhaon BK. Delayed internal fixation of fractures of the neck of the femur in young adults. A prospective, randomised study comparing closed and open reduction.The Journal of bone and joint surgery British volume. 2004;86(7):1035-40.

7. Wongwai T, Wajanavisit W, Woratanarat P. Non-union and avascular necrosis of delayed reduction and screw fixation in displaced femoral neck fracture in young adults. Journal of the Medical Association of Thailand = Chotmaihet thangphaet. 2012;95 Suppl 10:S120-7.

8. Wang W, Wei J, Xu Z, Zhuo W, Zhang Y, Rong H, et al. Open reduction and closed reduction internal fixation in treatment of femoral neck fractures: a meta-analysis. BMC musculoskeletal disorders. 2014;15:167.

9. Garden RS. Stability And Union In Subcapital Fractures Of the Femur. The Journal of bone and joint surgery British volume. 1964;46:630-47.

10. Lindequist $S$, Tornkvist H. Quality of reduction and cortical screw support in femoral neck fractures. An analysis of 72 fractures with a new computerized measuring method.Journal of orthopaedic 
trauma. 1995;9(3):215-21.

11. Barnes R, Brown JT, Garden RS, Nicoll EA. Subcapital fractures of the femur. A prospective review.The Journal of bone and joint surgery British volume. 1976;58(1):2-24.

12. Garden RS. Reduction and fixation of subcapital fractures of the femur.The Orthopedic clinics of North America. 1974;5(4):683-712.

13. Kang JS, Moon KH, Shin JS, Shin EH, Ahn CH, Choi GH. Clinical Results of Internal Fixation of Subcapital Femoral Neck Fractures.Clinics in orthopedic surgery. 2016;8(2):146-52.

14. Karanicolas PJ, Bhandari M, Walter SD, Heels-Ansdell D, Sanders D, Schemitsch E, et al. Interobserver reliability of classification systems to rate the quality of femoral neck fracture reduction. Journal of orthopaedic trauma. 2009;23(6):408-12.

15. Min BW, Kim SJ. Avascular necrosis of the femoral head after osteosynthesis of femoral neck fracture.Orthopedics. 2011;34(5):349.

16. Tianxing Wang $\varangle$ Guoqing LiهYang Wang, Baochao Ji. Analysis of influencing factors of femoral head necrosis after closed reduction and hollow compression screw fixation of femoral neck fracture.

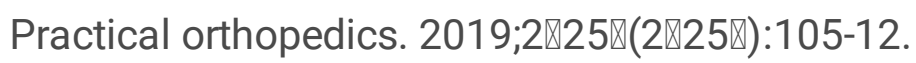

17. Wang CT, Chen JW, Wu K, Chen CS, Chen WC, Pao JL, et al. Suboptimal outcomes after closed reduction and internal fixation of displaced femoral neck fractures in middle-aged patients: is internal fixation adequate in this age group? BMC musculoskeletal disorders. 2018;19(1):190.

18. Florschutz AV, Langford JR, Haidukewych GJ, Koval KJ. Femoral neck fractures: current management. Journal of orthopaedic trauma. 2015;29(3):121-9.

19. Papapietro N, Di Martino A, Niccoli G, Palumbo A, Salvatore G, Forriol F, et al. Trabecular metal screw implanted for avascular necrosis of the femoral head may complicate subsequent arthroplasty surgery. European journal of orthopaedic surgery \&traumatology : orthopedie traumatologie. 2014;24(6):931-8.

20. Bachiller FG, Caballer AP, Portal LF. Avascular necrosis of the femoral head after femoral neck fracture.Clinical orthopaedics and related research. 2002(399):87-109.

21. Guimaraes JAM, Rocha LR, Noronha Rocha TH, Bonfim DC, da Costa RS, Dos Santos Cavalcanti A, et al. Vertical femoral neck fractures in young adults: a closed fixation strategy using a transverse cancellous lag screw. Injury. 2017;48 Suppl 4:S10-S6.

\section{Figures}



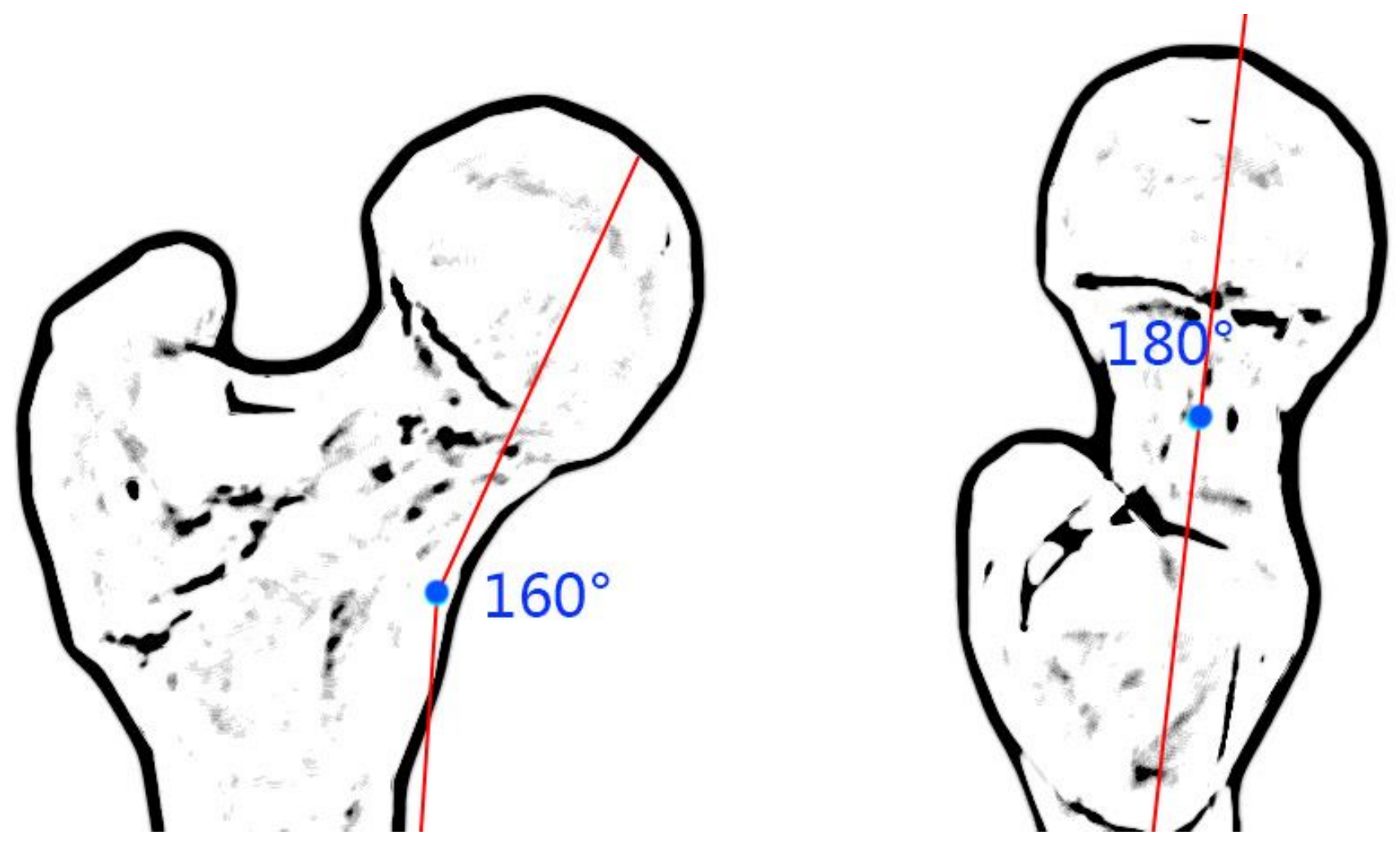

Figure 1

Schematic diagram of the measurement of the positive side x-ray of the Garden Index with satisfactory satisfaction
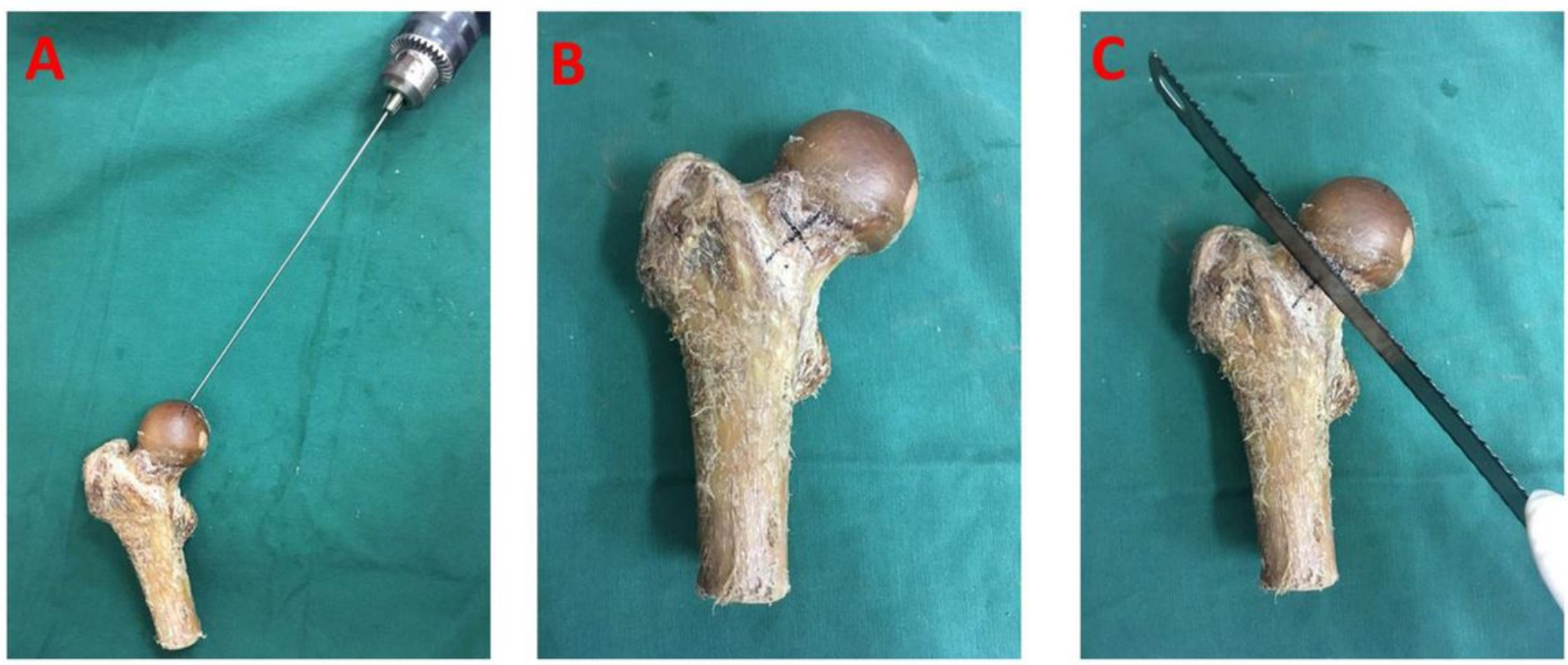

Figure 2

Insertion of the Kirschner wire before the osteotomy, concentric circular saw osteotomy $₫ A$ : central positioning of the femoral head before osteotomy; B: marking of the femoral neck osteotomy; C: through the osteotomy line, vertical femoral neck osteotomy. 


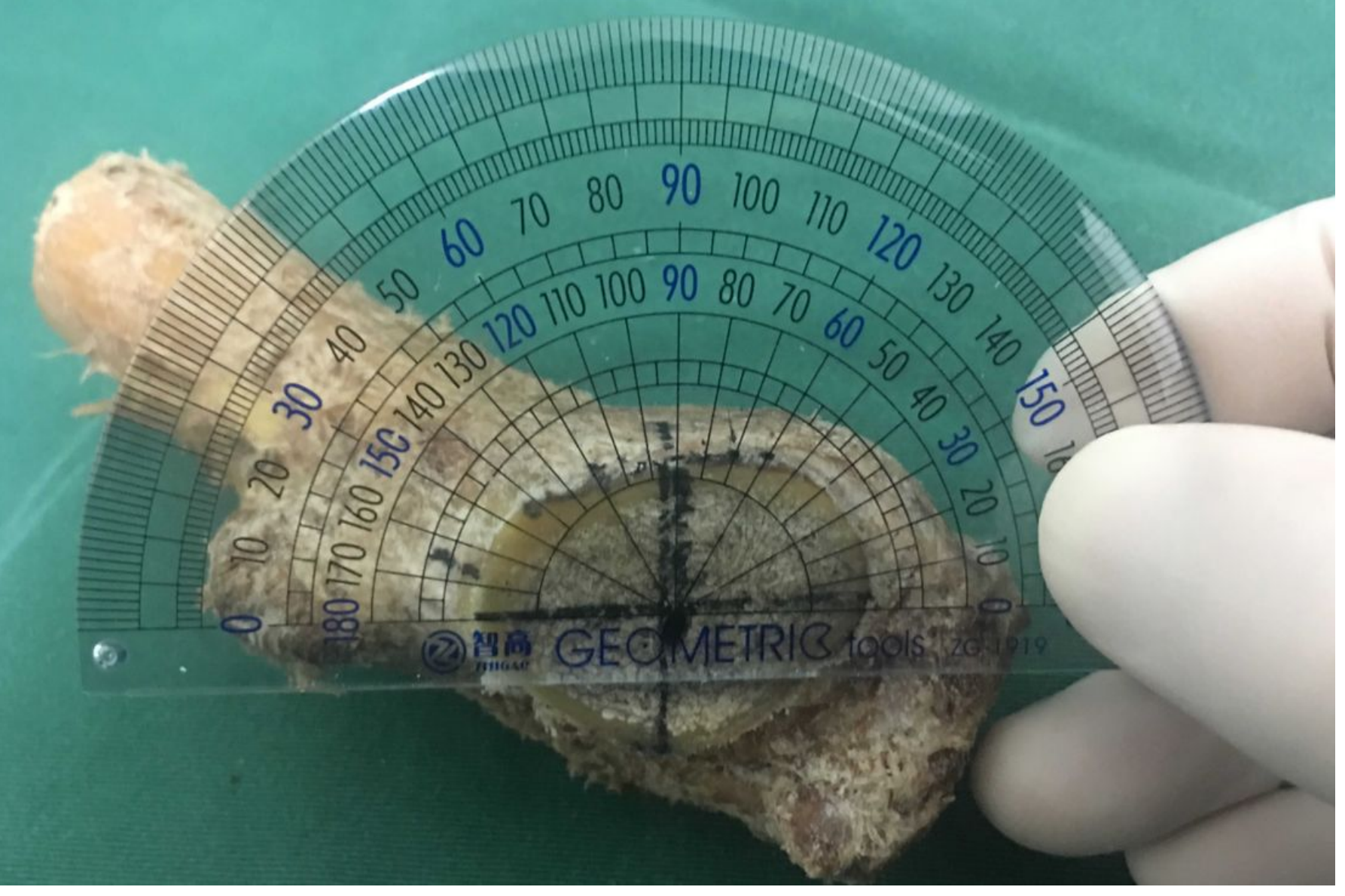

Figure 3

Scale production
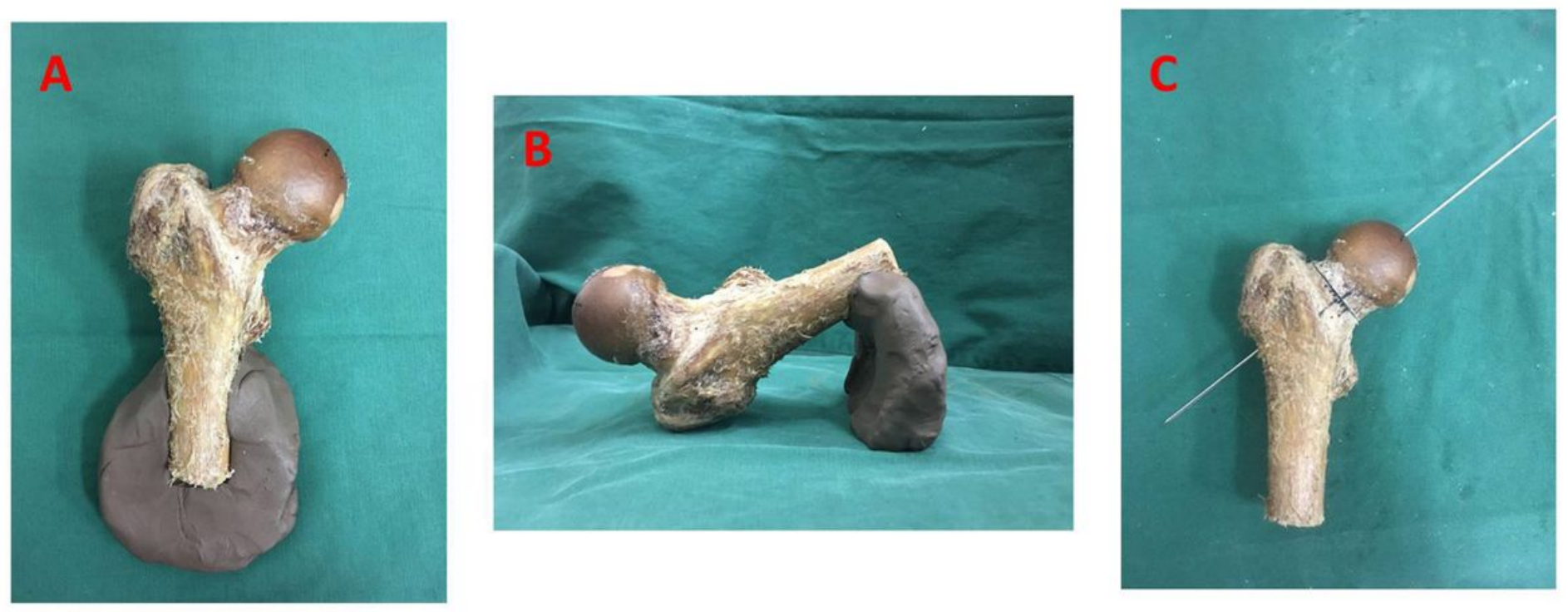

Figure 4 
The femoral head rotation model makes the anterior and lateral position: A model fixed anterior position; B: model fixed lateral position; C: osteotomy model fixation diagram
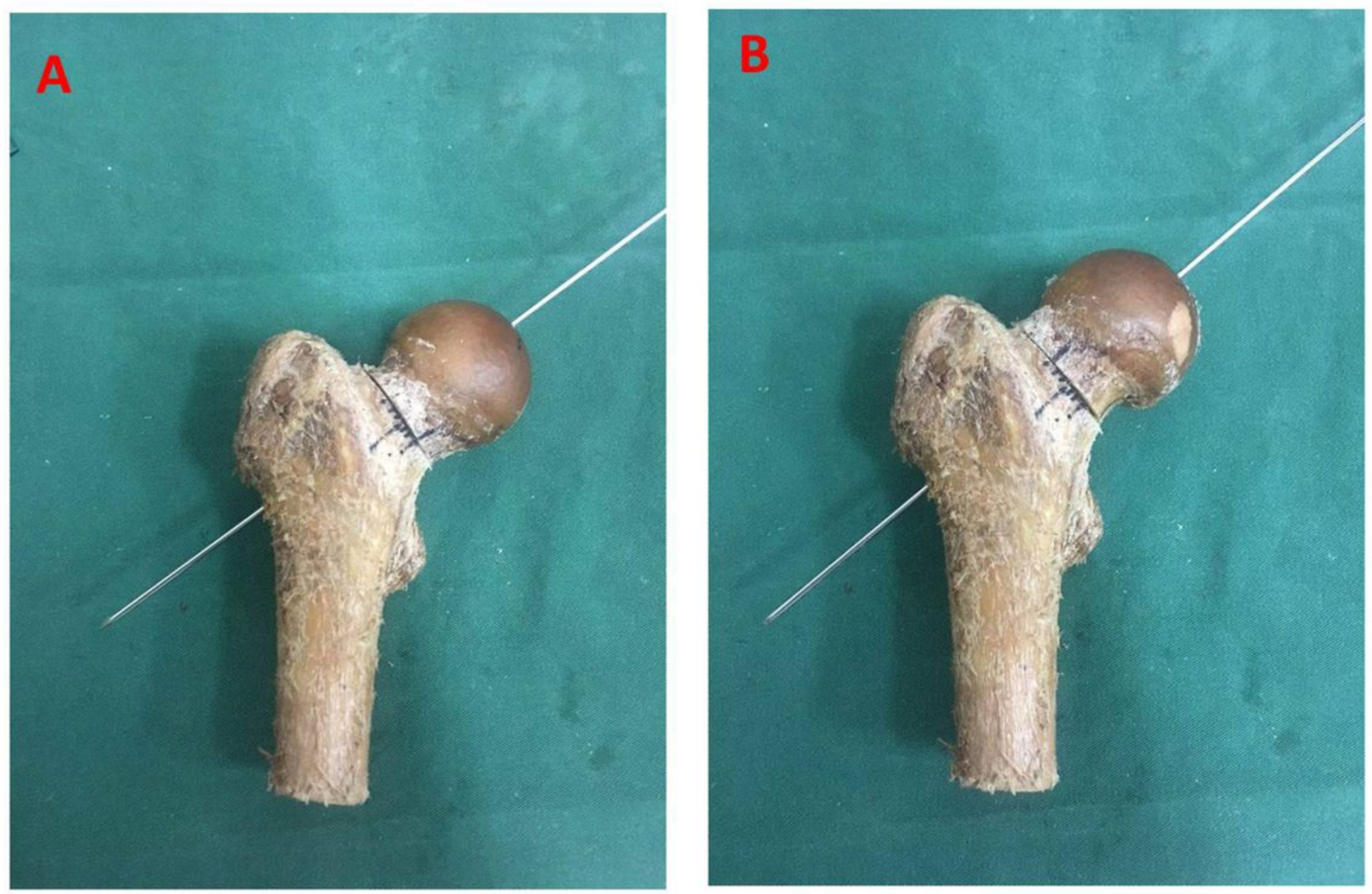

\section{Figure 5}

Schematic diagram of the rotation of the proximal model of the femoral head: $A: 30^{\circ}$ pronation; $B$ : $30^{\circ}$ supination 


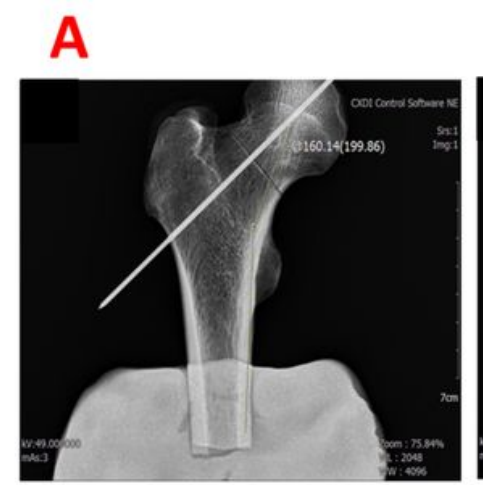

no rotation

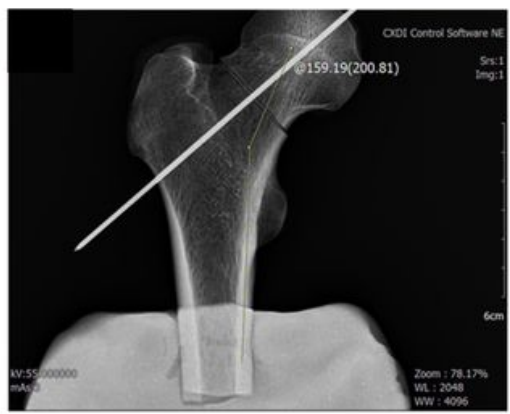

$30^{\circ}$ pronation

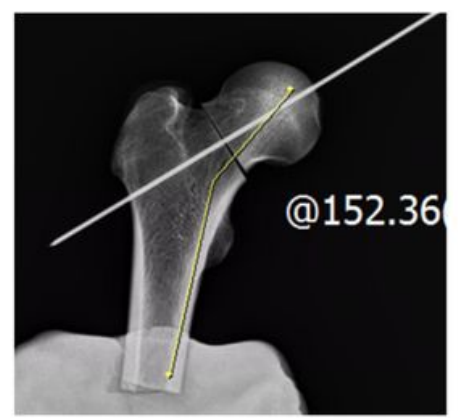

$40^{\circ}$ pronation

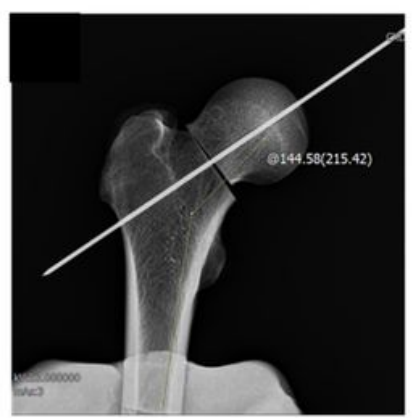

$70^{\circ}$ pronation

B

\begin{tabular}{|l|l|}
\hline group $(\mathrm{n}=10)$ & Garden index in AP-view \\
\hline no rotation & $160.2 \pm 0.34$ \\
\hline $10^{\circ}$ pronation & $160.2 \pm 0.31$ \\
\hline $20^{\circ}$ pronation & $160.1 \pm 0.12$ \\
\hline $30^{\circ}$ pronation & $159.7 \pm 0.3$ \\
\hline $40^{\circ}$ pronation & $152.4 \pm 1.41$ \\
\hline $50^{\circ}$ pronation & $146 \pm 1.64$ \\
\hline $70^{\circ}$ pronation & $144 \pm 0.60$ \\
\hline $90^{\circ}$ pronation & $141.7 \pm 0.60$ \\
\hline F & 912.56 \\
\hline P & 0.001 \\
\hline
\end{tabular}

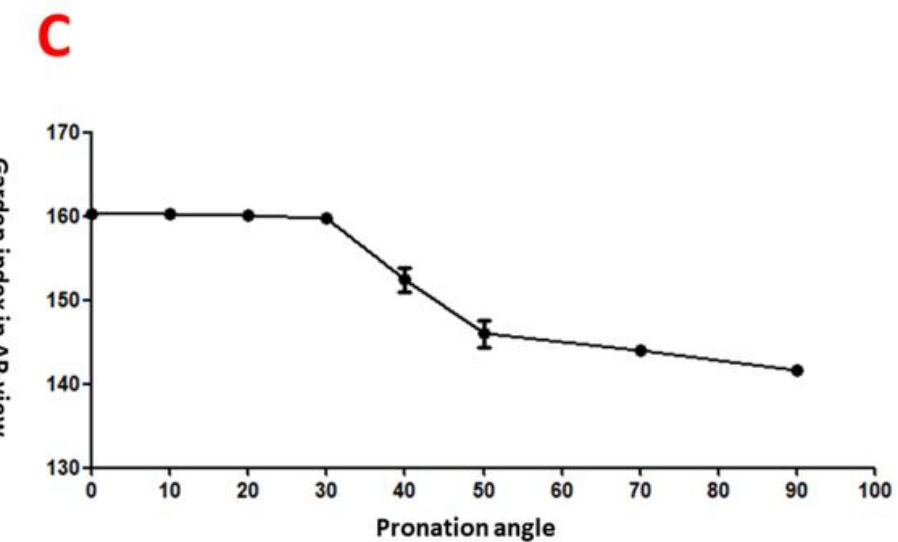

\section{Figure 6}

When the femoral head is pronation, the antero-posterior phase garden index changes: A: no rotation to the $90^{\circ}$ pronation, the antero-posterio phase garden index does not change significantly before $30^{\circ}$, and $40^{\circ}$ begins to change significantly; $B$ : Analysis of variance showed that there was a statistical difference between the groups during the pronation of the femoral head; $\mathrm{C}$ : the line graph clearly showed the trend of the garden index. 


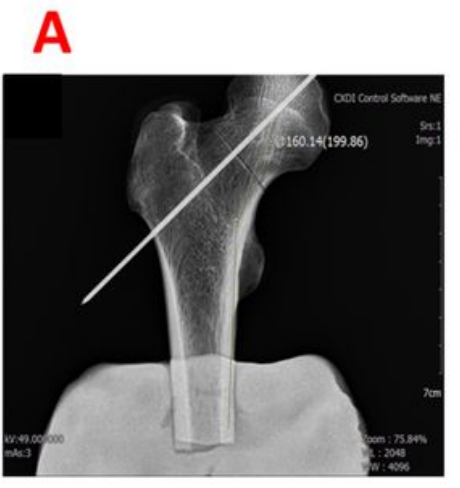

no rotation

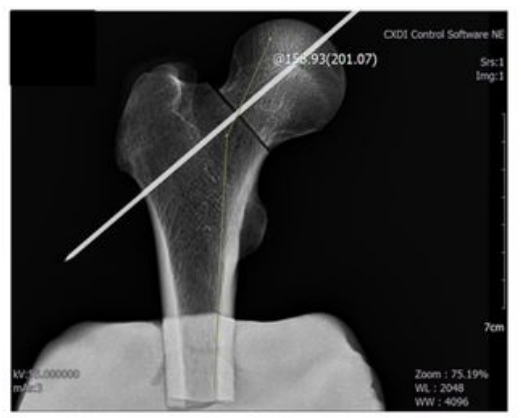

$30^{\circ}$ supination

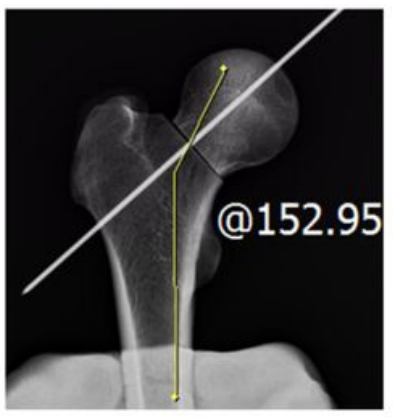

$40^{\circ}$ supination

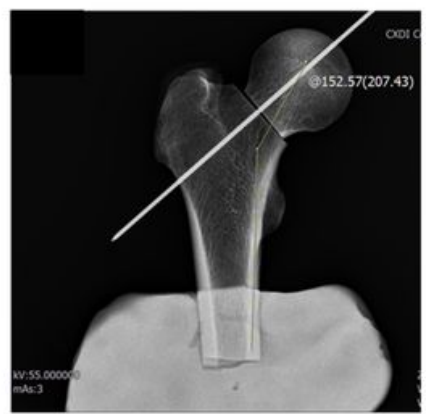

$70^{\circ}$ supination
B

\begin{tabular}{|c|c|}
\hline group(n=10) & Garden index in AP-view \\
\hline no rotation & $160.2 \pm 0.34$ \\
\hline $10^{\circ}$ supination & $159.7 \pm 0.71$ \\
\hline $20^{\circ}$ supination & $159.1 \pm 0.52$ \\
\hline $30^{\circ}$ supination & $158.6 \pm 0.43$ \\
\hline $40^{\circ}$ supination & $151.7 \pm 1.06$ \\
\hline $50^{\circ}$ supination & $147.3 \pm 1.82$ \\
\hline $70^{\circ}$ supination & $142.8 \pm 0.75$ \\
\hline $90^{\circ}$ supination & $139.9 \pm 1.48$ \\
\hline$F$ & 653.98 \\
\hline $\mathbf{P}$ & 0.001 \\
\hline
\end{tabular}

C

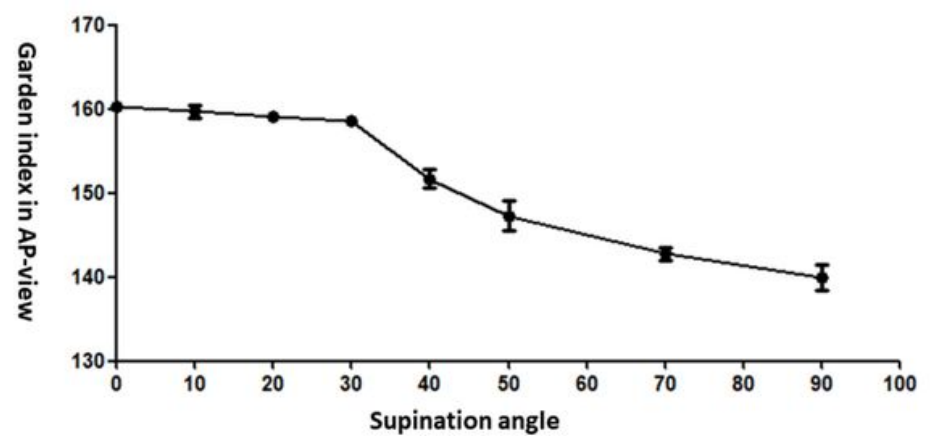

\section{Figure 7}

When the femoral head is supination, the antero-posterior phase garden index changes: A: no rotation to the $90^{\circ}$ supination, the antero-posterio phase garden index does not change significantly before $30^{\circ}$, and $40^{\circ}$ begins to change significantly; $B$ : Analysis of variance showed that there was a statistical difference between the groups during the supination of the femoral head; $\mathrm{C}$ : the line graph clearly showed the trend of the garden index. 
A

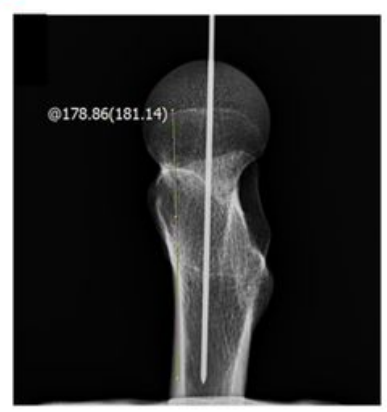

no rotation

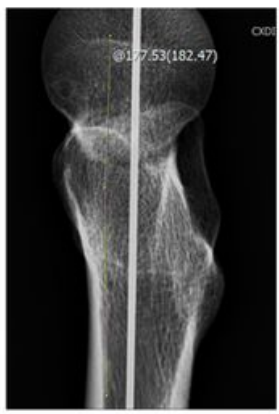

$30^{\circ}$ pronation

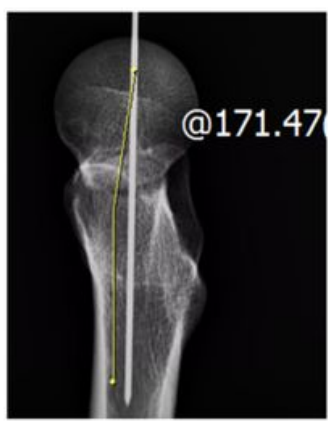

$40^{\circ}$ pronation

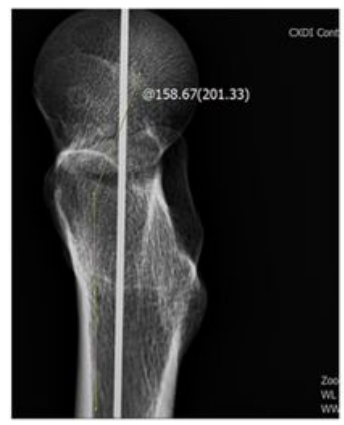

$70^{\circ}$ pronation

B

\begin{tabular}{|c|c|}
\hline group $(n=10)$ & Garden index in lateral view \\
\hline no rotation & $179.2 \pm 0.78$ \\
\hline $10^{\circ}$ pronation & $179.2 \pm 0.62$ \\
\hline $20^{\circ}$ pronation & $178.6 \pm 0.92$ \\
\hline $30^{\circ}$ pronation & $177.3 \pm 0.6$ \\
\hline $40^{\circ}$ pronation & $172.5 \pm 0.86$ \\
\hline $50^{\circ}$ pronation & $168.6 \pm 0.98$ \\
\hline $70^{\circ}$ pronation & $157.2 \pm 1.17$ \\
\hline $90^{\circ}$ pronation & $156.5 \pm 1.63$ \\
\hline $\mathbf{F}$ & 927.17 \\
\hline $\mathbf{P}$ & 0.001 \\
\hline
\end{tabular}

C

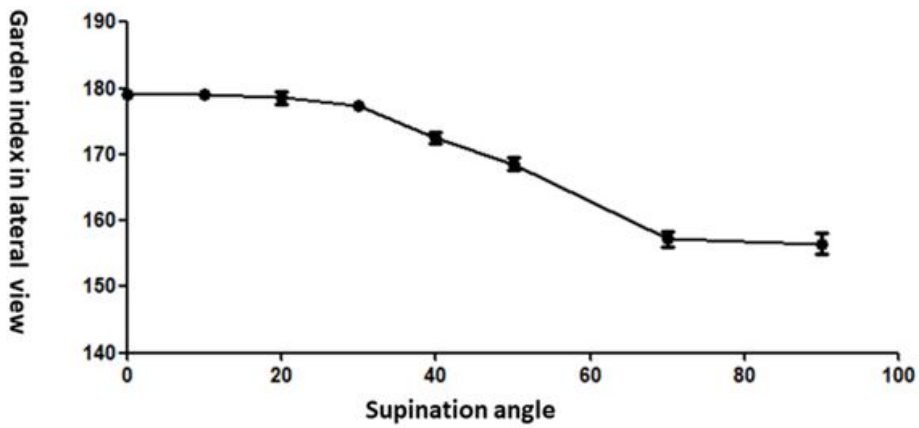

\section{Figure 8}

When the femoral head is pronation, the lateral phase garden index changes: A: no rotation to the $90^{\circ}$ pronation, the lateral phase garden index does not change significantly before $30^{\circ}$, and $40^{\circ}$ begins to change significantly; $\mathrm{B}$ : Analysis of variance showed that there was a statistical difference between the groups during the pronation of the femoral head; $\mathrm{C}$ : the line graph clearly showed the trend of the garden index. 
A

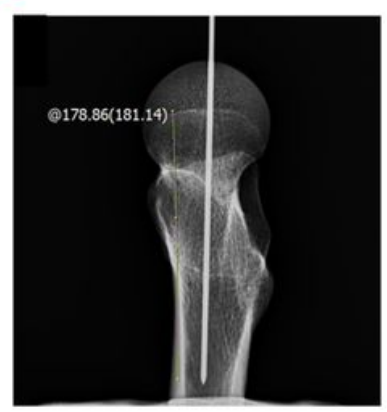

no rotation

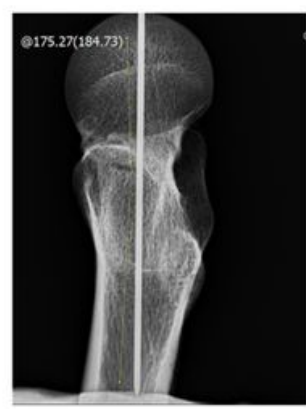

$30^{\circ}$ supination

B

\begin{tabular}{|l|l|}
\hline group $(\mathrm{n}=10)$ & Garden index in lateral view \\
\hline no rotation & $179.2 \pm 0.78$ \\
\hline $10^{\circ}$ supination & $179.4 \pm 0.6$ \\
\hline $20^{\circ}$ supination & $178.4 \pm 0.56$ \\
\hline $30^{\circ}$ supination & $176.5 \pm 1.16$ \\
\hline $40^{\circ}$ supination & $172.3 \pm 0.79$ \\
\hline $50^{\circ}$ supination & $166.8 \pm 1.02$ \\
\hline $70^{\circ}$ supination & $155.7 \pm 1.74$ \\
\hline $90^{\circ}$ supination & $154.2 \pm 1.27$ \\
\hline F & 966.78 \\
\hline P & 0.001 \\
\hline
\end{tabular}

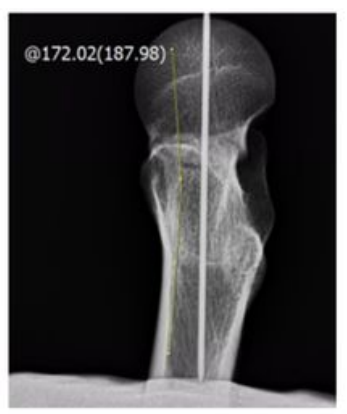

$40^{\circ}$ supination

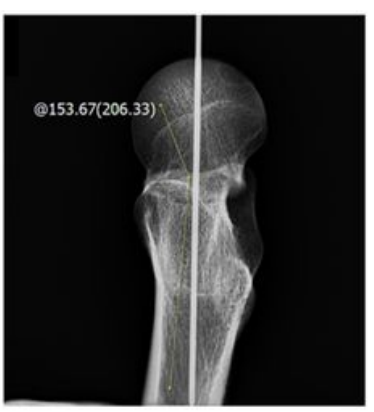

$70^{\circ}$ supination

C

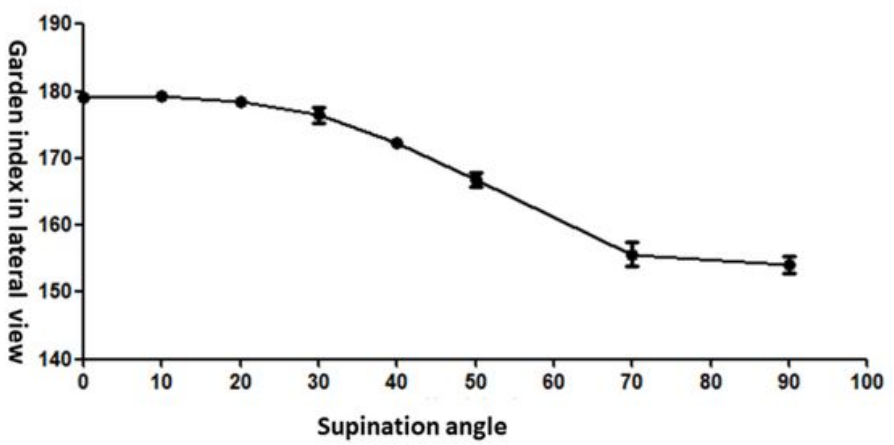

\section{Figure 9}

When the femoral head is supination, the lateral phase garden index changes: A: no rotation to the $90^{\circ}$ supination, the lateral phase garden index does not change significantly before $30^{\circ}$, and $40^{\circ}$ begins to change significantly; B: Analysis of variance showed that there was a statistical difference between the groups during the supination of the femoral head; $\mathrm{C}$ : the line graph clearly showed the trend of the garden index. 
A

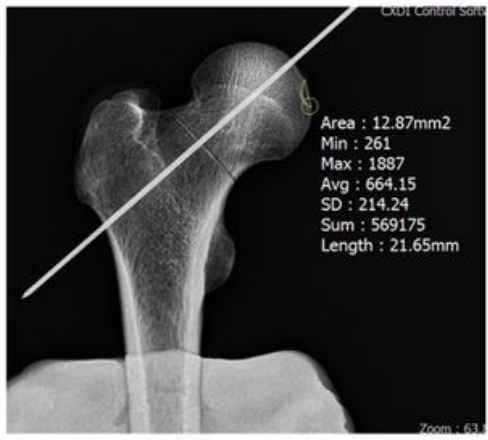

B no rotation

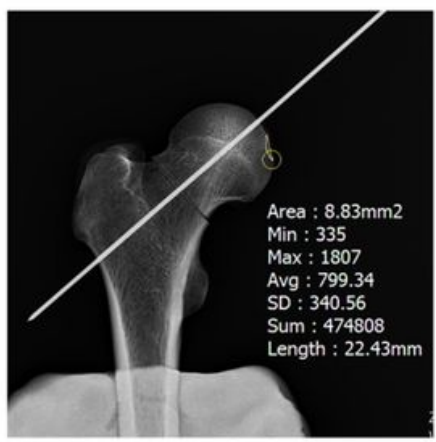

$30^{\circ}$ pronation

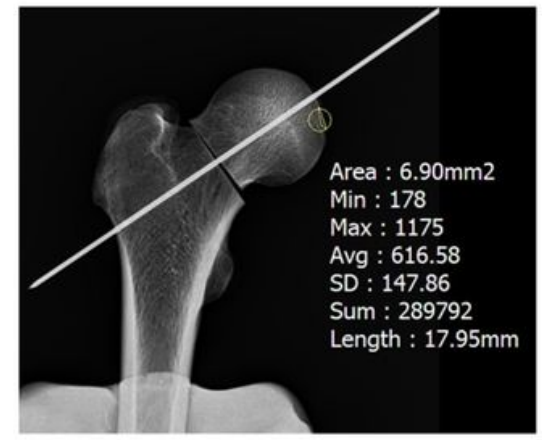

$60^{\circ}$ pronation

\begin{tabular}{|l|l|}
\hline group $(\mathrm{n}=10)$ & fovea area size of femoral head $\left(\mathrm{mm}^{2}\right)$ \\
\hline no rotation & $12.67 \pm 0.77$ \\
\hline $10^{\circ}$ pronation & $9.85 \pm 0.19$ \\
\hline $20^{\circ}$ pronation & $9.08 \pm 0.2$ \\
\hline $30^{\circ}$ pronation & $8.56 \pm 0.26$ \\
\hline $40^{\circ}$ pronation & $8.30 \pm 0.26$ \\
\hline $50^{\circ}$ pronation & $7.22 \pm 0.21$ \\
\hline $60^{\circ}$ pronation & $6.58 \pm 0.29$ \\
\hline
\end{tabular}

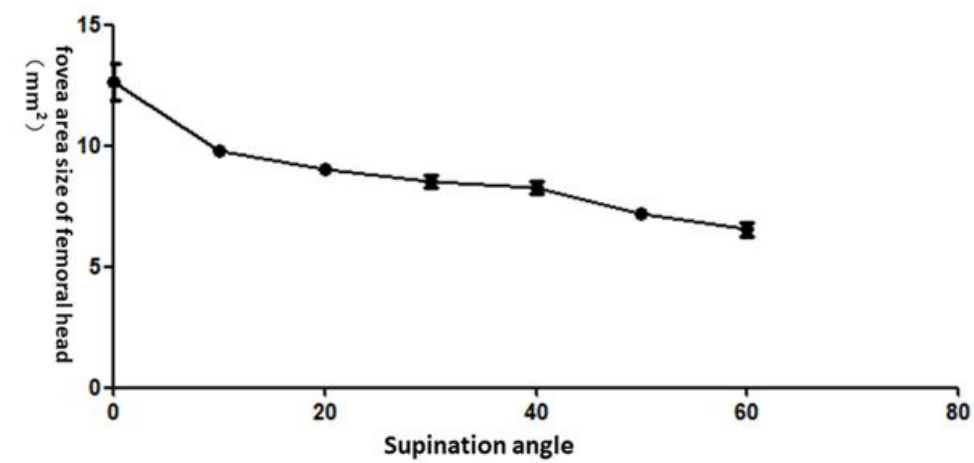

Figure 10

When the femoral head is pronation, the change of the fovea area of femoral head in the anteriorposterior view: $A$ : the fovea area of femoral head is gradually reduced during the process of not rotating to the pronation $60^{\circ} ; \mathrm{B}$ : The value of the fovea area of femoral head corresponding to each angle during the pronation process; $\mathrm{C}$ : The line diagram clearly shows the change trend of the fovea area of femoral head. 


\section{A}

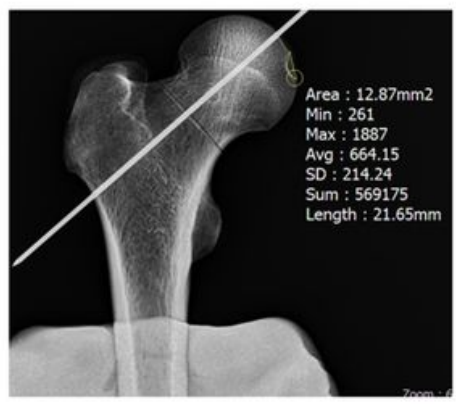

no rotation

B

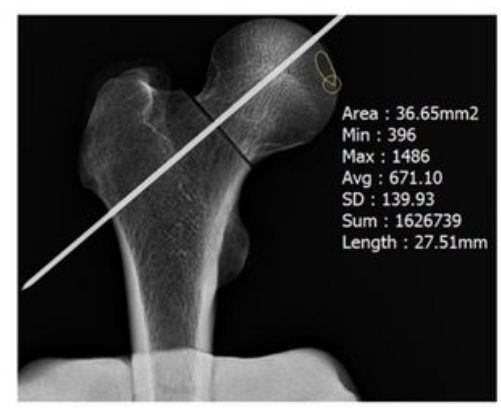

$30^{\circ}$ supination

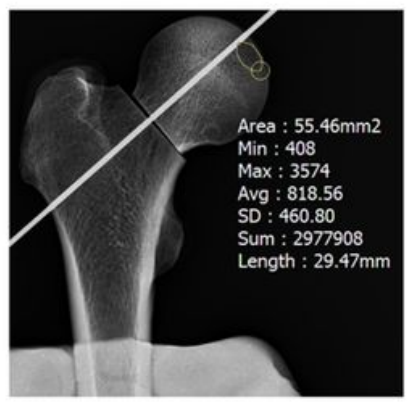

$60^{\circ}$ supination

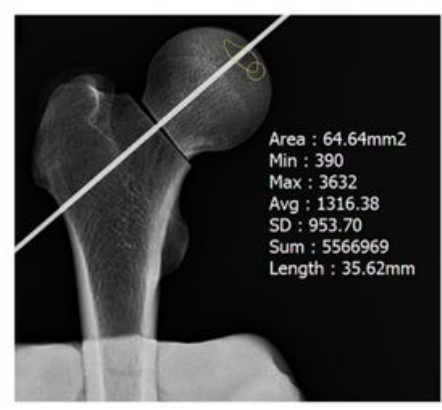

$90^{\circ}$ supination

C

\begin{tabular}{|l|l|}
\hline group $(n=10)$ & fovea area size of femoral head $\left(\mathrm{mm}^{2}\right)$ \\
\hline no rotation & $12.67 \pm 0.77$ \\
\hline $10^{\circ}$ supination & $22.8 \pm 1.46$ \\
\hline $20^{\circ}$ supination & $31.3 \pm 1.53$ \\
\hline $30^{\circ}$ supination & $36.3 \pm 1.39$ \\
\hline $40^{\circ}$ supination & $51.3 \pm 1.02$ \\
\hline $50^{\circ}$ supination & $53.04 \pm 1.27$ \\
\hline $70^{\circ}$ supination & $56.9 \pm 1.48$ \\
\hline $90^{\circ}$ supination & $65.4 \pm 1.18$ \\
\hline
\end{tabular}

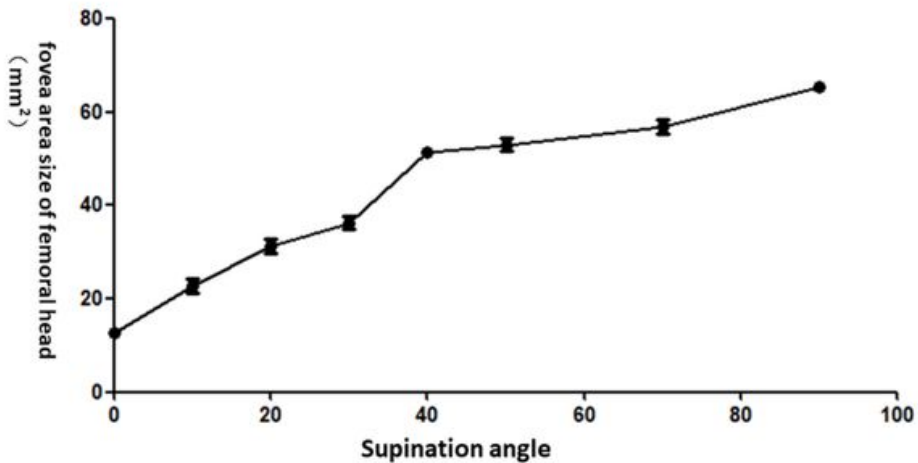

\section{Figure 11}

When the femoral head is supination, the change of the fovea area of femoral head in the anteriorposterior view: A: the fovea area of femoral head is gradually increases during the process of not rotating to the supination $90^{\circ} ; \mathrm{B}$ : The value of the fovea area of femoral head corresponding to each angle during the supination process; $\mathrm{C}$ : The line diagram clearly shows the change trend of the fovea area of femoral head. 